\title{
Study on the Shortage and Reconstruction of Chinese
}

\author{
Ecological Tax System
}

\author{
Min Niu, Liangliang He \& Jie Jiang \\ Law Department \\ Nanjing University of Information Science and Technology \\ Nanjing 210044, China \\ Tel: 86-025-5869-9931_E-mail: joeyang111@hotmail.com
}

\begin{abstract}
Guiding by the view of science-based development, the ecological tax system which also possesses the benefits of encouragement and financing capital should be gradually established, so the material benefits can stimulate and drive that the social pollution costs are translated into production costs and market price, and the policy and law objectives to control ecological pollution and improve ecological quality can be realized. According to the requirements of sustainable development, China present tax system should be adjusted, and the relatively perfect ecological tax system should be gradually established. In this article, we put forward main countermeasures including the taxation to ecological pollution tax, the reform to resource tax system, and the adjustments to corresponding articles of other tax types about environmental protection.
\end{abstract}

Keywords: Ecological tax, Ecological pollution tax, Ecological resource tax

\section{The basic frame and functions of the ecological tax system}

The ecological tax means many tax types and special taxation system composed by a series of taxation measures that are imposed by the country for realizing special ecological objective, raising environmental capital and strengthening taxpayers' environmental activities, and it includes special tax types and relative regulations aiming at pollution ecology, the behaviors or products destroying the ecological balance, various tax adjustment measures to protect the ecology and relative contents about environmental protection contained in other tax types.

The special ecological protection tax includes the ecological pollution tax imposed to contaminations or pollution behaviors and the ecological resource tax imposed to rare resources or the behaviors utilizing or destroying natural resources (Xu, 2001, p.22). The existing ecological tax types imposed by various countries include (1) the pollution tax, i.e. the direct tax which is directly associated with actual pollution values (or evaluation values) and computed by the pollution amount, (2) the product tax or material tax, i.e. the indirect tax to commodity or service which mainly aims at the products which produce pollutions in the production process or in the consumption and disposal process, (3) the special tax to finance capital for the environmental protection. The relative ecological tax measures include (1) the tax payout, i.e. derating the behaviors or establishments that are propitious to the environmental protection, for example, implementing derating or drawback to the investments of energy-saving or low pollution equipments for encouraging environmental investments, and implementing tax derating to some technology transfer fees for encouraging environmental technology research, and implementing tax-free to the recycle of old and waste goods for encouraging the recycle of the equipments, (2) tax difference, i.e. implementing low tax rate for the beneficial ecological products and imposing high tax rate for the products harming the ecology, (3) other relative environmental protection regulations contained in other tax types.

The ecological tax can make a price for the ecological resources and number the price into the cost that enterprise or personnel utilized the ecological resource, realize interior translation of the exterior cost, change the market price signals to rectify the consumption and production behaviors which harm the ecology. The income of ecological tax can establish the special sustainable develop fund that the government fathers and guarantee the ecological resources except for paying relative costs about management, supervision and compulsive implementation.

The ecological tax is the important encouragement tool exerted in the ecological management by the country, which objective is to exert the double functions of taxation, i.e. the encouragement and capital financing through the 
establishment of ecological economic benefit stimulation mechanism, translate the social costs of ecological pollution and destruction into the production costs and market prices, and finally realize controlling ecological pollution and improving ecological quality in policies and laws through the resource distribution of the market.

\section{The actuality and shortage of China ecological tax system}

\subsection{The pollution charge system}

The adjustment to pollution behavior, the compensation to ecological infraction and the financing to prevention capital in the present stage in China are mainly realized by the pollution charge system, and the special tax type aiming at the pollution behaviors or products is lacked, and the system in the Regulation of Effluent Fees Collection, Usage and Management which has the character of quasi-tax has many shortages.

(1) The charge standard is relatively low. The present charge standard of China was instituted by the environmental protection department with the price department in 1988, which is far lower than the treatment cost of pollution, and the enterprise exceeding pollution fee only corresponds with $10 \%-15 \%$ of the treatments cost of pollution, and it is owed charge in fact and it only induces the situation of "who causes the pollution, who benefits".

(2) The taxation range is too narrow. The pollution charge is only paid by enterprises, and many non-enterprises are foreclosed from the main bodies of pollution, and the charge doesn't bring effluvium matter, part industrial solid wastes, living garbage and electromagnetic wave radicalization into the range of taxation.

(3) The taxation evidences are not reasonable. The present pollution exceeding charge system of China doesn't impose enterprises which are on or under the pollution standard, which can not ensure and improve the ecological quality. The exceeding charge according to the pollution concentration without considering the pollution amount would prick up the pollutions to resource and ecology to large extents. The charge according to single factor goes against cutting pollution material as a whole and makes managers in the unequal competitive state.

(4) Problems exist in the taxation management. The pollution taxation lacks legal proofs and quantitative standard, and its rigidity and authority are deficient, and the resistance of taxation is large. The professional environmental departments are lacked, so the taxation efficiency is low, the costs are too high and the capital management is confused.

(5) The whole validity of capital usage is bad. The local environmental protection bureau imposes the pollution charge and hand it in to the finance of same class in the stated time, and the charge is directly translated into the special management fund which belongs to the capital out of budget and possesses characters such as independence, specially using and separation, and only is used in end pollution treatment, induces the capital separation and "hard" budget restriction to enterprises. When the region of taxation objective differs with the region of ecological influence, it also may induce some "vacuum" zones of ecological management, and in the actual operation, the proportion that is used in the self-construction and usual expenditure for the environmental protection department are too large.

(6) The legal "hard injury" of exceeding pollution charge exists. The pollution standard belongs to compulsive standard, and the doer must be punished through money even criminal responsibility, but now the present exceeding pollution behaviors only form the pollution charge condition but not the illegal behavior, so the legislation conflict would induce interior disharmony of law system and the charge should be further clarified and modified.

\subsection{Golden ecological industrial development}

Following abuses exist in the present resource taxation.

(1) The character orientation is unreasonable. The present resource tax of China is only the adjustment measure to adjust the income level difference among resource exploitation enterprises, and it can not embody the interior value of resource, can not realize the interior translation of social exploitation cost, and can not help enterprises change their economic increase mode, and can not become into the interior power to reduce the resource consumption and improve the production equipments and technics flow.

(2) The taxation range is too narrow. The taxation objectives are limited in mine resource, which can not effectively protect ground resource, water resource, animal and plant resource and other natural resources, induces unreasonable parity of successive products after resources and stimulates the ravening exploitation to non-tax resources.

(3) The tax computation evidences are not reasonable. In China, the sales amount of products exploited and produced by taxpayers is the taxation evidence, which makes enterprises pay no resource taxes based on exploitation and sale, directly encourage unordered exploitation and induces overstock and waste of large of resource.

(4) The unit tax amount is low. The unit tax amount of China resource tax is lower, which limits the adjustment space and weakens the functions of resource protection and using adjustment (Wu, 2008, p.44).

\subsection{Other assistant tax types with ecological protection function and taxation measures}

In the present tax system frame of China, the tax types involving ecological protection include consumption tax, urban maintenance and construction tax, business income tax, housing property tax, tenure tax, vehicle and vessel usage 
license plate tax and so on, and the content is disperse and the regulation is not complete, which can not really affect consumption behavior or production behavior. The taxation measures mainly are the taxation favors with single content limited in direct favor or favor after the event, which can not effectively restrain the ecological pollution and reduce the energy consumption (Cao, 2006, p.93).

\section{The reconstruction of China ecological tax system}

\subsection{The legislation system of ecological tax}

The theory and practice research of ecological tax are mainly centralized in western developed countries (especially in countries of OECD) which constituted special tax laws about ecological and resource protection early or late, imposed special tax type aiming at various behaviors or products destroying ecology and developing and utilizing natural resources, clearly regulated numerous concrete tax types by the form of law, adjusted contorted direct taxes and indirect taxes that had negative effects in traditional taxes, cancelled taxation articles which didn't according with the requirement of environmental protection and sustainable development, and realized the ecology and green of tax system (The Research Group of "Environmental Tax System” of China Taxation Academy, 2000, p.42).

China only added assistant tax adjustment measures in general tax legislations such as income tax, value added tax, consumption tax and product tax, and the perfect ecological tax system has not been established. The science-based development view should be uncompromisingly carried out, and the beneficial experiences of western countries should be used for reference, and China present tax system should be adjusted according to the requirement of sustainable development and concrete national situation, and the important objective of China tax construction is to gradually establish relative perfect ecological tax system.

\subsection{Establishing the ecological pollution tax system}

(1) The design of tax type. According to present ecological problems and environmental protection policy, the ecological pollution tax should be imposed designedly and starting from main pollution sources and easy tax objective, and gradually transforming from pollution charge to the ecological pollution tax. In present stage, the water pollution tax, atmosphere pollution tax (carbon tax and sulfur dioxide tax), solid waste tax and other tax types should be imposed.

(2) The design of taxpayer. All ratepaying main bodies including pollution enterprises and individuals should be limitedly deleted according to taxation efficiency, control and other factors in practice. According to the minimum principal of easy taxation and taxation fee, China taxpayer of the ecological pollution tax should give priority to beneficial pollution main bodies, adopt tax transfer modes such as commodity hidden tax to realize the intention of tax, and implement deferment or conditional taxation to individual denizens.

(3) The design of tax computation evidence. There are three selections of the ecological pollution tax for the evidence computation. The first one is the contamination amount, which can directly push pollution reduced course, but the corresponding supervision cost and technical requirement are very high. The water pollution tax and the sulfur dioxide tax adopt this type of tax base. The second one is the output of pollution enterprises, which convenient for the taxation from the headspring, and enterprises only can reduce the tax through the decrease of product or service output, and the stimulation that producers develop technology development and research for pollution treatment can not be realized. The carbon tax and solid waste tax generally adopt this type of tax base. The third one is harmful matter amount in the production factors or the consumption products, which can encourage taxpayers actively search relative replacements for raw materials, but can not impel enterprises apply themselves to reduce pollutions.

(4) The design of tax rate. It includes four aspects. The first one is the form of tax rate. Based on the character of waste let and the simplified principle of tax system, the tax rate structure of the ecological pollution tax should not be complex, and the ration tax rate should be adopted. The second one is the amount of tax rate. The tax should be limited in the compensation of exterior cost and exceed the control cost that enterprises pay for cutting pollution. In practice, the treatment objective is confirmed first, and then the treatment cost is confirmed, i.e. under the established ecological quality standard, the tax rate is confirmed combining with pollution treatment marginal charge. The third one is the uniformity of tax rate. Because the situations of climate condition, economic development level, population density and the demands of ecological cleanness degree are different, difference tax rates should be implemented according to the marginal influencing degree of pollution amount. The fourth one is the fixity of tax rate. The marginal cost of ecological control is changing with the improvement of control technology, so the relative tax rate should be properly adjusted to make the pollution control costs minimized in every special term.

(5) The design of taxation and management mode. The taxation and management should be implemented by the tax department and the environmental protection department together, and the former supervises the pollution sources periodically and offers various tax computation data, and the later imposes tax taxes according to confirmed pollution amount and supervises and manages taxpayers, which can fully exert the specialties of both departments and enhance the taxation and management efficiency. 


\subsection{Perfecting the ecological resource tax system}

(1) Establishing the resource tax system with ownership. As the representative of resource owner, the government has right to share resource benefits with resource development enterprises together, and in the setup of tax system, the intention that imposes resource tax for keeping within limits of unlimited exploitation for natural resources should be fully expressed, and the prices of the resource ownership (irreproducible resource exploitation right ) and the usage right (reproducible resource periodical exploitation right) that the government transfers should be reasonably confirmed.

(2) Expanding the taxation range of resource tax. The taxation range confirmed by the resource class table should include all irreproducible resources and the resources which repertories are on the critical level and which reproducible abilities have be obviously harmed, and if present taxation and management level can not impose all resources, at least, many reproducible resources such as water resource, forest resource, grass resource and infield resource with high quality which are all destroyed and wasted seriously should be included.

(3) Adjusting the tax computation evidence of the resource tax. The resource exploitation enterprises or personnel should pay for all exploited resources, but not only for the gained resources at present and the taxation mode according to the production amount can make resource exploiters start from their own benefits, fully consider the market demand, reasonably confirm the exploitation quantity of resources, and stop the waste of resources.

(4) Reasonably confirming the unit tax amount of the resource tax. When the unit tax amount of the resource tax is confirmed, following principles should be followed. The first one is to embody the transfer prices of low-grade resource ownership and access. The second one is to adjust the difference incomes among different resource exploitation grades. The third one is to include exterior costs of resource exploitation. The fourth one is to correctly reflect the interior value of resource. The fifth one is to consider the re-cultivation fund demand amount and establish marginal compensation fund. Through reasonably confirming the tax amount and changing the situation that resource-based industry overly depend on low cost resource, the resource economization and recycle usage can be improved (Xu, 2001, p.35).

\subsection{The adjustments to other tax articles with the effect of ecological tax}

To improve the green course of tax system in China, corresponding articles in other tax types should be adjusted for the environmental protection.

(1) Reforming the system of consumption tax. The taxation range of the consumption tax should be expanded. The products such as battery and once catering containers that can not be recycled and utilized or can induce serious ecological pollutions and can be replaced by corresponding "green products" should be brought into the tax range, and the different tax rates should be designed according the ecologically friendly degrees of different products and the usage of clean product should be encouraged.

(2) Perfecting the favored measure of tax. Except for keeping former tax favors such as tax reduction, tax-free and zero tax rate, various tax favored measures should be adopted aiming at concrete situations, for example, imposing high customs to the imported products that seriously pollute the ecology or may seriously pollute the ecology but are difficult disposed or have high disposal costs, derating customs to the imported products such as pollution disposal equipments, ecological supervision and research apparatus and ecological harmless technologies that can not be produced in China, adopting high custom rate to exported raw materials, primary products and manufactured goods consuming a great lot of resource, adopting lower custom rate to the imported ecological protective establishments and materials, implementing tax encouragement to the high and new environmental technologies, and implementing investment supports an reinvestment drawback to the enterprises investing in ecological treatment and protection projects for encouraging pollution treatment and improving the sustainable development of national economy.

\subsection{Some problems should be noticed in the reconstruction of the ecological tax system}

(1) Policy harmony. If the government can not consider possible ecological influences produced when it constitutes or implements macro policies, project policies and department policies, it will always contort the encourage mechanism, prick up the ecological depravation, so the government should notice assorting and harmonizing with other relative policies to avoid mutual collisions or deviations when it strengthens the construction of tax system.

(2) Law link. Relative laws should be modified to avoid the ecological tax conflicts with present ecological basic laws, regulations and other department laws, and the whole law system should be organically uniformed and surrounded the science-based development view.

(3) International collaboration. The ecological cycle is not restrained by the national boundaries and ideologies, and all economic and social developments in various countries will produce global ecological effects. The legislation activity of domestic ecological tax law should actively participate in bilateral or multilateral ecological tax harmony and cooperation and assume corresponding international obligations based on respecting national dominion and admitting regional differences. 


\section{References}

Cao, Mingde \& Wang, Jingxing. (2006). The Valuable Orientation and Reform Direction of China Environmental Tax System. Law Review. No.1. p.93.

The Research Group of "Environmental Tax System" of China Taxation Academy. (2000). Study on the Establishment of Environmental Protection Tax in China. Taxation Research. No.9. p.42.

Wu, Yajun. (2008). Green Tax Innovation and Chinese Sustainable Development Strategy. Economic Observer. No.2. p.44.

Xu, Fengguo. (2001). Circular Economy and Environmental Tax System Reform. Seeker. No.2. p.35.

Xu, Mengzhou, Tan, Baiping \& Xie, Zengyi. (2001). Thoughts on Chinese Legislation of Environment Duty. Beijing College of Political Science and Law. No.2. p.22. 